\title{
Randomized, Double-Blind Trial of the Effect of Fluid Composition on Electrolyte, Acid-Base, and Fluid Homeostasis in Patients Early After Subarachnoid Hemorrhage
}

\author{
Laura Lehmann - Stepani Bendel • Dominik E. Uehlinger • \\ Jukka Takala - Margaret Schafer • Michael Reinert • \\ Stephan M. Jakob
}

Published online: 8 August 2012

(C) Springer Science+Business Media, LLC 2012

\begin{abstract}
Background Hyper- and hyponatremia are frequently observed in patients after subarachnoidal hemorrhage, and are potentially related to worse outcome. We hypothesized that the fluid regimen in these patients is associated with distinct changes in serum electrolytes, acid-base disturbances, and fluid balance.

Methods Thirty-six consecutive patients with SAH were randomized double-blinded to either normal saline and hydroxyethyl starch dissolved in normal saline (Voluven ${ }^{\circledR}$; saline) or balanced crystalloid and colloid solutions (Ringerfundin $^{\circledR}$ and Tetraspan ${ }^{\circledR}$; balanced, $n=18$, each) for $48 \mathrm{~h}$. Laboratory samples and fluid balance were evaluated at baseline and at 24 and $48 \mathrm{~h}$.

Results Age $[57 \pm 13$ years (mean $\pm \mathrm{SD}$; saline) vs. $56 \pm 12$ years (balanced)], SAPS II (38 \pm 16 vs. $34 \pm 17)$,

Electronic supplementary material The online version of this article (doi:10.1007/s12028-012-9764-3) contains supplementary material, which is available to authorized users.
\end{abstract}

Registered with the Deutsches Register Klinischer Studien, trial number DRKS000034.

\footnotetext{
L. Lehmann $\cdot$ S. Bendel $\cdot$ J. Takala $\cdot$ M. Schafer .

S. M. Jakob ( $\square)$

Department of Intensive Care Medicine, Bern University

Hospital (Inselspital) and University of Bern, 3010 Bern,

Switzerland

e-mail: stephan.jakob@insel.ch

L. Lehmann

e-mail: 1.lehmann@sui.ch

S. Bendel

e-mail: Stepani.Bendel@kuh.fi

J. Takala

e-mail: jukka.takala@insel.ch
}

Hunt and Hess [3 (1-4) (median, range) vs. 2 (1-4)], and Fischer scores [3.5 (1-4) vs. 3.5 (1-4)] were similar. Serum sodium, chloride, and osmolality increased in saline only ( $p \leq 0.010$, time-group interaction). More patients in saline had $\mathrm{Cl}>108 \mathrm{mmol} / \mathrm{L}$ [16 (89 \%) vs. 8 (44\%); $p=0.006]$, serum osmolality $>300 \mathrm{mosmol} / \mathrm{L}[10(56 \%)$ vs. $2(11 \%)$; $p=0.012]$, a base excess $<-2[12(67 \%)$ vs. $2(11 \%)$; $p=0.001]$, and fluid balance $>1,500 \mathrm{~mL}$ during the first $24 \mathrm{~h}[11(61 \%)$ vs. 5 (28 \%); $p=0.046]$. Hyponatremia and hypo-osmolality were not more frequent in the balanced group.

Conclusions Treatment with saline-based fluids resulted in a greater number of patients with hyperchloremia, hyperosmolality, and positive fluid balance $>1,500 \mathrm{~mL}$ early after SAH, while administration of balanced solutions did not cause more frequent hyponatremia or hypo-osmolality. These results should be confirmed in larger studies.

Keywords Subarachnoid hemorrhage - Fluid therapy · Osmolality · Acid-base balance

\author{
M. Schafer \\ e-mail: margaret.schafer@insel.ch \\ D. E. Uehlinger \\ Department of Nephrology and Hypertension, Bern University \\ Hospital (Inselspital) and University of Bern, 3010 Bern, \\ Switzerland \\ e-mail: uehlinger@mph.unibe.ch \\ M. Reinert \\ Department of Neurosurgery, Bern University Hospital \\ (Inselspital) and University of Bern, 3010 Bern, Switzerland \\ e-mail: mmv.reinert@insel.ch
}




\section{Introduction}

Serum sodium concentration and fluid balance are frequently abnormal in patients after subarachnoid hemorrhage (SAH) $[1,2]$, with dysnatremia causing morbidity in patients with SAH [3-5]. Moreover, in other critically ill or emergency patient populations, both severe hyper- and hyponatremia are associated with persistent neurological deficits and high mortality [6-8]. Traditionally, patients with cerebral insults receive sodium chloride containing fluids (normal saline) for baseline and substitution requirements. The rationale for this approach is to avoid fluid shifts across a damaged blood-brain barrier and subsequent brain edema, both of which can occur if more physiological, slightly hypoosmolar types of fluids are used $[9,10]$. Nevertheless, this has never been shown in patients after SAH. In addition, normal saline has been associated with metabolic acidosis and slower urinary output in volunteers [11] and with metabolic acidosis and hyperkalemia in patients undergoing kidney transplantation [12] compared with lactated Ringer's solutions. On the other hand, balanced IV solutions were able to prevent the development of hyperchloremic metabolic acidosis, and provided better gastric mucosal perfusion compared with saline-based fluids in elderly surgical patients [13].

The infusion of saline increases natriuresis and consequently water diuresis. However, expanding the extracellular volume by sodium administration may also cause tissue edema. Consequently, liberal administration of saline and saline-based colloids may contribute to a disequilibrium in salt and water balance, and ultimately to morbidity in these patients.

The aim of this hypothesis-generating study was to evaluate the physiology of electrolyte and water homeostasis in patients after SAH using two different blinded fluid regimens. We hypothesized that an approach with saline-based fluids would result in hypernatremia, hyperchloremia, and hyperchloremic metabolic acidosis, with more frequent serum hyper-osmolality and less wellmaintained fluid balance compared to a regimen with a more physiological fluid composition. Since prediction of the magnitude of the postulated effects was difficult, we chose to randomize the patients to the treatment for only 2 days.

\section{Methods}

The study was approved by the Ethics Committee of the Canton of Bern, Switzerland. Inclusion and exclusion criteria were evaluated by an independent physician prior to study start, and deferred written informed consent was obtained from a close family member within $48 \mathrm{~h}$ after admission to the intensive care unit. A previous study including 36 volunteers assigned to saline versus balanced infusion reported significant differences in $\mathrm{pH}$, serum osmolality, and sodium concentration [11]. Accordingly, we aimed to include 18 patients per group. Consecutive emergency patients $>18$ years with a history of SAH were included. Patients were treated according to the standard clinical procedure at the Bern University Hospital, which included early surgical or endovascular intervention and the use of nimodipine. Blood pressure was kept low before the intervention (clipping or coiling; systolic blood pressure $100-120 \mathrm{mmHg}$ ) and normal to slightly elevated afterward $(120-160 \mathrm{mmHg})$. The baseline fluid administration rate was $1.5 \mathrm{~mL} / \mathrm{kg} / \mathrm{h}$, and substitution was performed with crystalloids and colloids at approximately a 1:1 ratio when clinical signs of hypovolemia developed (low blood pressure and/or low urinary output $[<0.5 \mathrm{~mL} / \mathrm{kg} / \mathrm{h}]$ in the presence of low peripheral skin temperature, and/or decreased capillary refill or central/peripheral venous filling). Baseline fluid rate was increased if the prescribed hemodynamic goals were not achieved despite several volume challenges, and decreased if clinical or radiological signs of fluid overload developed. The clinical status of the patients was continually observed by the treating nurse, and hemodynamic and clinical parameters recorded and displayed in a patients data management system (Clinisoft, GE, Helsinki, Finland). This system displays trends over time of each registered parameter which facilitates the interpretation of hemodynamic status evolution. Each patient was visited at least once every $8 \mathrm{~h}$ by the treating physician, and twice daily by a research nurse. At ICU admission, patients were randomized to a blinded volume regimen with either normal saline and hydroxyethyl starch dissolved in normal saline (Voluven $^{\circledR}$, Fresenius Kabi AG, Bad Homburg, Germany) or balanced crystalloid and colloid solutions (Ringerfundin ${ }^{\circledR}$ and Tetraspan ${ }^{\circledR}$, B. Braun Medical AG, Sempach, Switzerland). The composition of the different fluids is displayed in Table S1 of the electronic supplement. Fluids were prepared by non-blinded nurses who were not involved in the treatment of the patients. Fluid bags were wrapped in opaque plastic bags and labeled as "crystalloid" or "colloid" to ensure blinding. The randomized treatment was continued for $48 \mathrm{~h}$.

The following parameters were measured and evaluated at baseline and at 24 and $48 \mathrm{~h}$ : serum sodium, potassium, chloride, osmolality, glucose, creatinine, troponine, TSH, fT3, fT4, and plasma cortisol, and urine sodium, potassium, chloride, osmolality, and creatinine. Total fluid and sodium balances were measured and osmolar and free water clearances were calculated at 24-h intervals. The balances included baseline fluids, fluids administered to achieve the prescribed hemodynamic goals, enteral nutrition, and all fluids administered with drugs delivered as infusions or by syringe pumps. 
For the assessment of neurological outcome, the modified Rankin scale was used [14]. The modified Rankin Scale is commonly used for measuring the degree of disability or dependence in the performance of daily activities. It ranges from 0 (perfect health without symptoms) to 6 (death).

\section{Statistical Analysis}

The SPSS 16.0 software package (SPSS Inc. ${ }^{\circledR}$, Chicago, IL, USA) was used for statistical analysis, and statistical significance was considered at $p<0.05$. Normal distribution was assessed by the Kolmogorov-Smirnov test. For variables with repeated measurements, differences between groups were assessed by analysis of variance using one dependent variable, one between-subject factor (saline vs. balanced), and one within-subject factor (time). For non-normally distributed data, non-parametric ANOVA for repeated measurements (Friedman Test) was used separately in both groups after comparison of baseline data with the Mann-Whitney $U$ test. Since 10 out of the 36 patients stayed less than two full days in the ICU, baseline and 24-h measurements were primarily included in ANOVA, followed by comparisons between 24- and 48-h measurement in each group separately (paired $t$ test or Wilcoxon test). Variables assessed only twice (fluid balances and diuresis) were compared between groups using unpaired $t$ tests at each time point. Categorical data were assessed using Fisher's exact test. Data are reported as mean $\pm \mathrm{SD}$ or as median (range).

\section{Results}

18 patients were randomized to sodium-based fluid treatment (group sodium) and 18 patients to balance-based fluid treatment (group balanced). Demographic and severity-ofillness data are displayed in Table 1. The incidence of specific comorbidities other than arterial hypertension was $<15 \%$ in each group. Three patients in the saline group and seven patients in the balanced group stayed less than $48 \mathrm{~h}$ in the ICU.

There were no differences in the use of norepinephrine ( $n=5$ in group saline vs. $n=6$ in group balanced), corticosteroids $(n=11$ in group saline vs. $n=6$ in group balanced), opioids, or antibiotics between the study groups.

Fluid and electrolyte administration and balances during the first $24 \mathrm{~h}$ and from 24 to $48 \mathrm{~h}$ are indicated in Table 2 . Included in the administered fluids were also fluids given in attempting to reach the prescribed hemodynamic goals $[1,090 \pm 1,450 \mathrm{~mL}$ (first $24 \mathrm{~h}$ ), and $680 \pm 1,210 \mathrm{~mL}$ (from 24 to $48 \mathrm{~h}$; saline group), and $750 \pm 1,170 \mathrm{~mL}$
Table 1 Demographic data

\begin{tabular}{lll}
\hline & $\begin{array}{l}\text { Saline group } \\
(N=18)\end{array}$ & $\begin{array}{l}\text { Balanced group } \\
(N=18)\end{array}$ \\
\hline Age (years) & $57 \pm 14$ & $56 \pm 12$ \\
Male/female & $6 / 12$ & $6 / 12$ \\
SAPS II & $38 \pm 16$ & $34 \pm 17$ \\
Admission GCS & $11(4-15)$ & $12(7-15)$ \\
Hunt and Hess grade & $3(1-4)$ & $3(1-4)$ \\
Hunt and Hess grade 3 or 4 & 10 & 7 \\
Fischer score & $3(1-4)$ & $3(1-4)$ \\
History of art. hypertension & 9 & 8 \\
Mechanical ventilation & 10 & 8 \\
Troponin I (ng/mL) & $1.5(0.00-0.11)$ & $0(0-3.15)$ \\
& $(N=7)$ & $(N=11)$ \\
\hline
\end{tabular}

SAPS simplified acute physiology score, GCS Glasgow Coma Scale

Table 2 Administered fluids and electrolytes, diuresis, and fluid balance

\begin{tabular}{lcc}
\hline & $\begin{array}{l}\text { Saline group } \\
N=18\end{array}$ & $\begin{array}{l}\text { Balanced group } \\
N=18\end{array}$ \\
Baseline to $24 \mathrm{~h}$ & $\begin{array}{l}N=15 \\
\text { (mean } \pm \mathrm{SD} \text { ) }\end{array}$ & $\begin{array}{l}N=11 \\
\text { (mean } \pm \mathrm{SD} \text { ) }\end{array}$ \\
\hline Crystalloids (mL) & & \\
Baseline to $24 \mathrm{~h}$ & $2,320 \pm 1,400$ & $2,250 \pm 730$ \\
Baseline to $48 \mathrm{~h}$ & $4,320 \pm 1,640$ & $4,500 \pm 2,300$ \\
Colloids (mL) & & \\
Baseline to $24 \mathrm{~h}$ & $1,750 \pm 1,370$ & $1,320 \pm 1,060$ \\
Baseline to $48 \mathrm{~h}$ & $3,030 \pm 1,620$ & $3,190 \pm 2,190$ \\
Sodium administered (mmol) & $541 \pm 228$ \\
Baseline to $24 \mathrm{~h}$ & $626 \pm 348$ & $1,153 \pm 657$ \\
Baseline to $48 \mathrm{~h}$ & $1,136 \pm 387$ & \\
Chloride administered (mmol) & $968 \pm 189$ \\
Baseline to $24 \mathrm{~h}$ & $624 \pm 348$ & $979 \pm 552$ \\
Baseline to $48 \mathrm{~h}$ & $1,129 \pm 387$ & \\
Total fluid input (mL) & & $4,780 \pm 4,940$ \\
Baseline to $24 \mathrm{~h}$ & $4,240 \pm 2,360$ & $9,420 \pm 5,090$ \\
Baseline to $48 \mathrm{~h}$ & $7,800 \pm 2,750$ & $3,220 \pm 2,090$ \\
Diuresis (mL) & & $5,960 \pm 4,180$ \\
Baseline to $24 \mathrm{~h}$ & $2,160 \pm 950$ & \\
Baseline to $48 \mathrm{~h}$ & $4,740 \pm 2,230$ & \\
Fluid balance $(\mathrm{mL})$ & & \\
Baseline to $24 \mathrm{~h}$ & $2,090 \pm 2,190$ & \\
Baseline to $48 \mathrm{~h}$ & $3,260 \pm 3,020$ & \\
\hline
\end{tabular}

(first $24 \mathrm{~h}$ ), and $870 \pm 1,760 \mathrm{~mL}$ (from 24 to $48 \mathrm{~h}$; balance group), respectively (NS)]. While the variables were similar in the two groups, sodium input was significantly higher than sodium excretion during the first $24 \mathrm{~h}$ in the saline group $[592 \pm 334$ vs. $206 \pm 177 \mathrm{mmol}(n=12)$; 
$p=0.005$ ), but not in the balanced group (496 \pm 246 vs. $334 \pm 307 \mathrm{mmol} \quad(n=9)$; n.s.]. A fluid balance of $>1,500 \mathrm{~mL}$ during the first $24 \mathrm{~h}$ was more frequent in patients in the saline group $[11(61 \%)$ vs. $5(28 \%)$; $p=0.046]$.

Patients with SAH Hunt and Hess grade 3 and 4 had higher fluid balances than patients with scores 1 and 2 (day 1: $2,360 \pm 2,060$ vs. $660 \pm 2,120 \mathrm{~mL} /$ day; $p=0.02$; day 2: $4,750 \pm 4,250$ vs. $1,500 \pm 2,360 \mathrm{~mL} /$ day; $p=0.03$ ). The differences of fluid input and diuresis between the two groups did not reach statistical significance. There was no association between fluid balance and a history of hypertension, corticosteroid or norepinephrine use, or serum concentrations of cortisol, TSH, fT3, and fT4.

Hemodynamic and intracranial pressure values are indicated in Table 3. Apart from a lower CVP in the balanced group at $24 \mathrm{~h}$, there were no differences between groups.

Changes in serum sodium, chloride, and osmolality over time are indicated in Figs. 1, 2 and 3. All variables increased in the saline group and remained unchanged in the balanced group (time-group interaction, all $p \leq 0.010$ ). Hyponatremia (serum sodium $<135 \mathrm{mmol} / \mathrm{L}$ ) occurred in two patients in the saline group and in none in the balanced group. More patients in the saline group experienced hyperchloremia $[\mathrm{Cl}>108 \mathrm{mmol} / \mathrm{L} ; 16(89 \%)$ vs. $8(44 \%) ; p=0.006]$. Serum hyper-osmolality ( $>300 \mathrm{mosmol} / \mathrm{L}$ ) occurred in 10

Table 3 Time course of hemodynamics and intracranial pressure

\begin{tabular}{lrll}
\hline & Saline group & $\begin{array}{l}\text { Balanced } \\
\text { group }\end{array}$ & Test, $p$ value \\
$N$ baseline (hemodyn/ICP) & $18 / 12$ & $18 / 8$ & \\
$N$ 24 h (hemodyn/ICP) & $18 / 13$ & $18 / 9$ & \\
$N 48$ h (hemodyn/ICP) & $11 / 12$ & $13 / 10$ & \\
\hline Systolic art. pressure (mmHg) & & & \\
Baseline & $129 \pm 23$ & $136 \pm 25$ & \\
24 h & $135 \pm 22$ & $141 \pm 20$ & \\
48 h & $135 \pm 15$ & $145 \pm 17$ & \\
Heart rate (beats/min) & & & \\
Baseline & $73 \pm 16$ & $71 \pm 12$ & \\
24 h & $72 \pm 11$ & $73 \pm 12$ & \\
48 h & $73 \pm 13$ & $71 \pm 10$ & \\
Central venous pressure (mmHg) & & \\
Baseline & $7 \pm 4$ & $8 \pm 5$ & TG, 0.002 \\
24 h & $10 \pm 3$ & $6 \pm 3$ & \\
48 h & $11 \pm 4$ & $10 \pm 3$ & \\
Intracranial pressure (mmHg) & $10 \pm 6$ & $11 \pm 7$ & \\
Baseline & $8 \pm 5$ & $12 \pm 4$ & \\
$24 \mathrm{~h}$ & $11 \pm 4$ & $9 \pm 3$ & \\
$48 \mathrm{~h}$ & & & \\
\hline
\end{tabular}

$T G$ time-group effect
$(56 \%)$ vs. $2(11 \%)$ patients $(p=0.012)$, and hypo-osmolality $(<285 \mathrm{mosmol} / \mathrm{L})$ in $4(22 \%)$ vs. $6(33 \%$; NS) patients in saline versus balanced groups. During the first

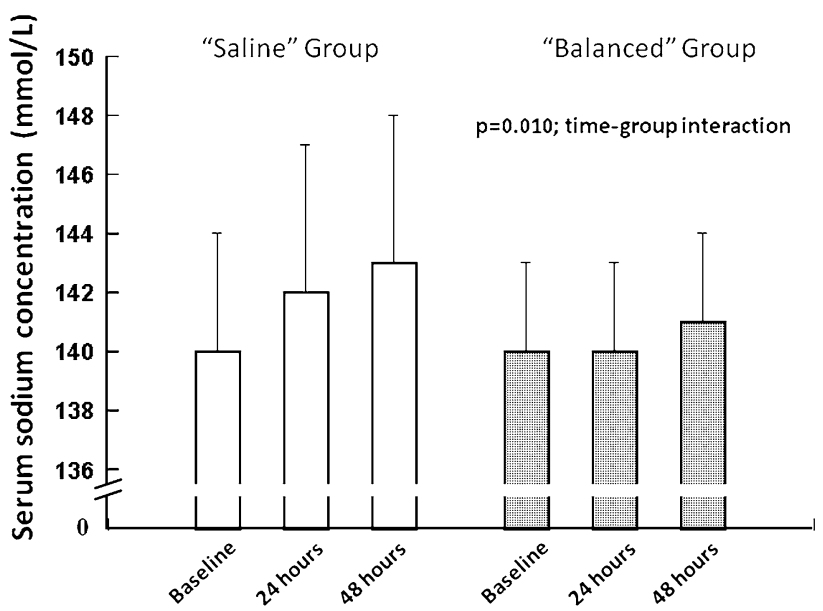

Fig. 1 Serum sodium concentrations at baseline, 24 and $48 \mathrm{~h}$

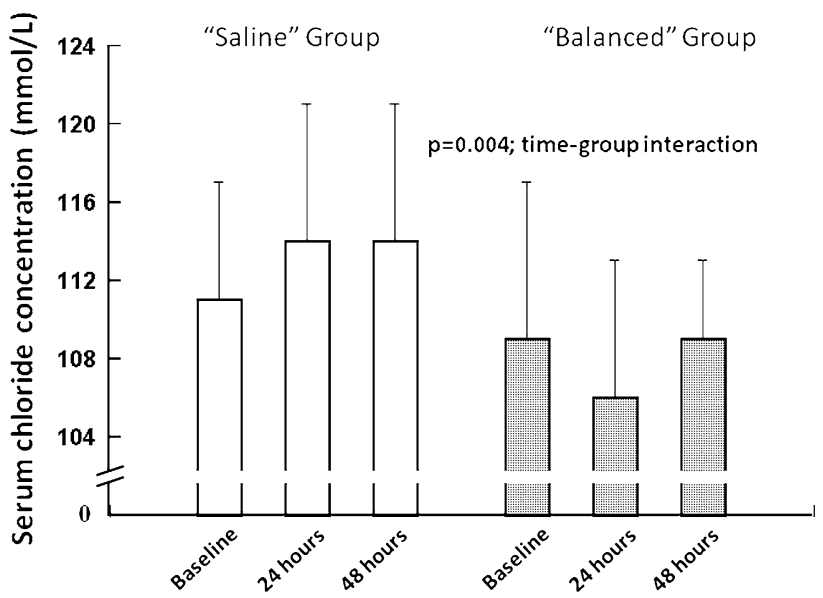

Fig. 2 Serum chloride concentrations at baseline, 24 and $48 \mathrm{~h}$

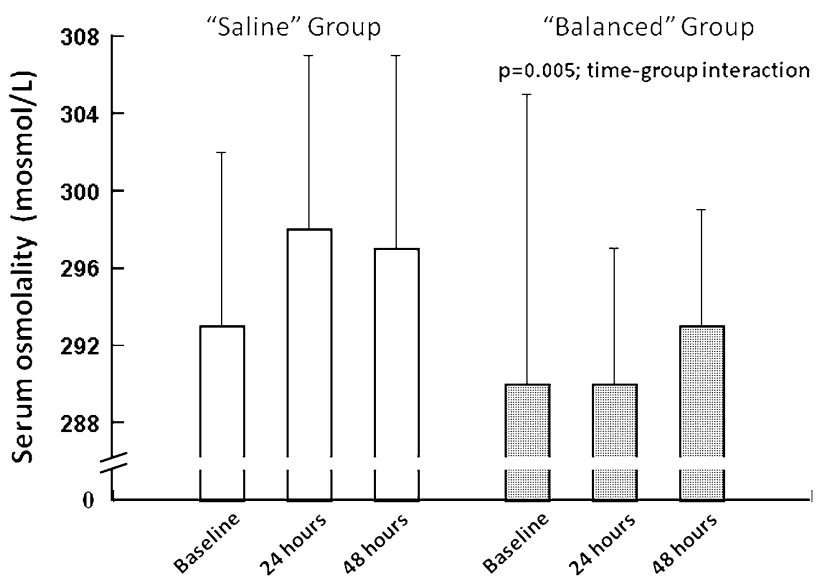

Fig. 3 Serum osmolality at baseline, 24 and $48 \mathrm{~h}$ 
day, serum potassium concentrations were similar (saline group, baseline: $3.8 \pm 0.6 \mathrm{mmol} / \mathrm{L}, 24 \mathrm{h:} 3.6 \pm 0.3 \mathrm{mmol} /$ $\mathrm{L}$, and balanced group $3.6 \pm 0.5 \mathrm{mmol} / \mathrm{L}$, and $3.5 \pm 0.3$ $\mathrm{mmol} / \mathrm{L}$ ), and then slightly increased in the balanced group (to $3.8 \pm 0.4 \mathrm{mmol} / \mathrm{L}, p=0.020$ ) but not in the saline group $(3.6 \mathrm{mmol} / \mathrm{L})$. Nine $(50 \%)$ patients in the saline group and $8(44 \%)$ in the balanced group experience hypokalemia $(<3.5 \mathrm{mmol} / \mathrm{L})$. At $24 \mathrm{~h}$, patients receiving norepinephrine had significantly lower potassium concentrations $(3.4 \pm 0.2 \mathrm{mmol} / \mathrm{L})$ than those who did not $(3.6 \pm 0.3 \mathrm{mmol} / \mathrm{L}, p=0.041)$.

Serum creatinine and urea were similar in both groups: creatinine of group saline versus group balanced was $56 \pm 14$ vs. $60 \pm 20 \mu \mathrm{mol} / \mathrm{L}$ at baseline and $52 \pm 11$ vs. $54 \pm 12$ $\mu \mathrm{mol} / \mathrm{L}$ (NS) at $48 \mathrm{~h}$. Urea was $5 \pm 3$ vs. $6 \pm 5 \mathrm{mmol} / \mathrm{L}$ at baseline and $4 \pm 2$ vs. $5 \pm 3 \mathrm{mmol} / \mathrm{L}$ (NS) at $48 \mathrm{~h}$.

Changes in arterial serum $\mathrm{pH}$ and base excess are shown in Figs. 4 and 5. pH increased in both groups (time effect, $p<0.012$ ). More patients in the saline group presented

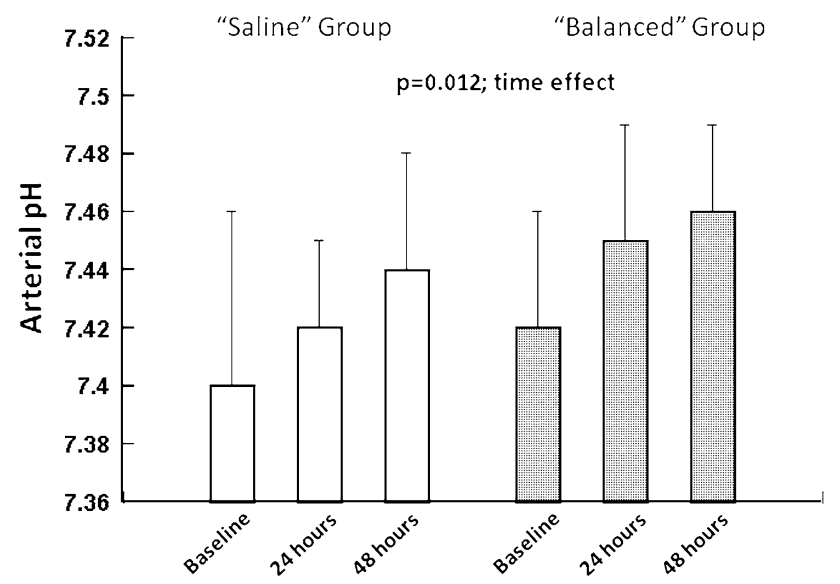

Fig. 4 Arterial $\mathrm{pH}$ at baseline, 24 and $48 \mathrm{~h}$

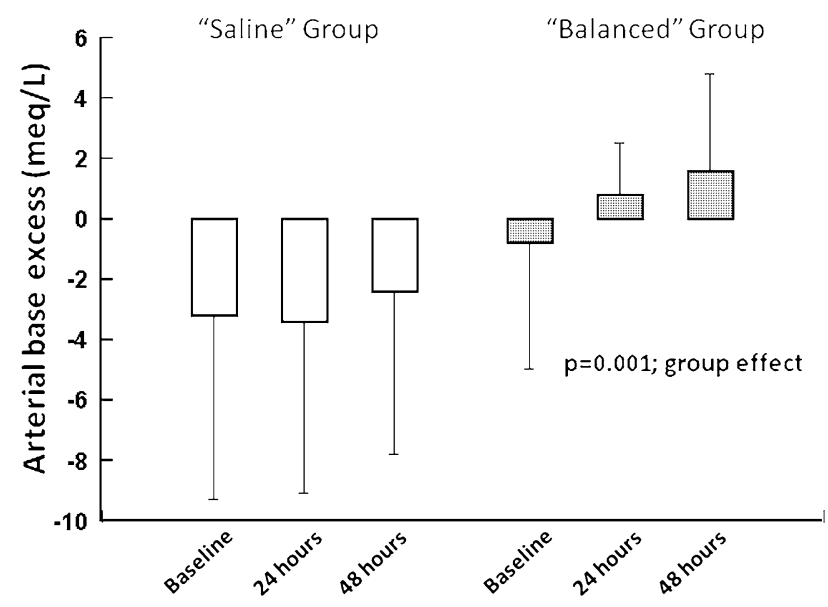

Fig. 5 Arterial base excess at baseline, 24 and $48 \mathrm{~h}$ with metabolic acidosis $[\mathrm{BE}<-2 ; 12(67 \%)$ vs. 2 $(11 \%) ; p=0.001]$.

Changes in cortisol, thyroid-stimulating hormone, free triiodothyronine, and thyroxine are indicated in Table 4. Cortisol and fT3 decreased in both study groups.

Urinary electrolytes and osmolality are indicated in Table 5. Urinary sodium concentrations remained similar between groups. At $48 \mathrm{~h}$, urine chloride concentrations were higher in the saline group $(132 \pm 42$ vs. $95 \pm 37 \mathrm{mmol} / \mathrm{L}$, $p=0.034)$. Differences in urine osmolality and potassium concentrations were not significant.

Osmolar clearance was similar in the saline and balanced groups (day 1: $3,900 \pm 2,280$ vs. $5,900 \pm 3,550 \mathrm{~mL} /$ day; day 2: $5,170 \pm 2,600$ vs. $4,590 \pm 2,280 \mathrm{~mL} /$ day; $N S$ ). There was also no difference in free water clearance (day 1 : $-1,840 \pm 1,680$ vs. $-2,660 \pm 2,030 \mathrm{~mL} /$ day; day $2:-$ $2,410 \pm 1,500$ vs. $-1,710 \pm 850 \mathrm{~mL} /$ day; NS).

Patients with SAH Hunt and Hess grades 3 and 4 tended to have both lower osmolar and free water clearance compared to patients with scores 1 and 2 (osmolar clearance day 1 : $3,700 \pm 1,920$ vs. $6,400 \pm 3,760 \mathrm{~mL} /$ day; $p=0.03$; day 2 : $7,860 \pm 3,560$ vs. $13,580 \pm 7,370 \mathrm{~mL} /$ day; $p=0.06$; free water clearance day $1:-1,960 \pm 1,000$ vs. $-3,030 \pm$ $2,230 \mathrm{~mL} /$ day; $p=0.13 ; \quad$ day $2:-3,870 \pm 1,800$ vs. $-6,730 \pm 3,380 \mathrm{~mL} /$ day; $p=0.05$ ).

Table 4 Time course of cortisol, TSH, fT3, and fT4

\begin{tabular}{|c|c|c|c|}
\hline $\begin{array}{l}N \text { baseline } \\
N 24 \mathrm{~h} \\
N 48 \mathrm{~h}\end{array}$ & $\begin{array}{l}\text { Saline group } \\
18 \\
18 \\
14\end{array}$ & $\begin{array}{l}\text { Balanced group } \\
18 \\
16 \\
10\end{array}$ & Test, $p$ value \\
\hline \multicolumn{4}{|c|}{ Cortisol (nmol/L) } \\
\hline Baseline & $1,014 \pm 893$ & $793 \pm 842$ & $\mathrm{~T}, 0.047$ \\
\hline $24 \mathrm{~h}$ & $540 \pm 286$ & $746 \pm 476$ & \\
\hline $48 \mathrm{~h}$ & $543 \pm 272$ & $494 \pm 281$ & \\
\hline \multicolumn{4}{|c|}{ TSH (mU/L) } \\
\hline Baseline & $1.17(0.2-3.1)$ & $1.36(0.3-4.9)$ & \\
\hline $24 \mathrm{~h}$ & $0.81(0.1-2.5)$ & $0.94(0.2-2.6)$ & \\
\hline $48 \mathrm{~h}$ & $0.82(0.1-2.6)$ & $0.95(0.2-2.6)$ & \\
\hline \multicolumn{4}{|c|}{ fT3 (pg/mL) } \\
\hline Baseline & $3.6(2.2-5.5)$ & $3.2(2.0-4.6)$ & $\mathrm{T}, 0.001$ \\
\hline $24 \mathrm{~h}$ & $2.7(1.8-4.1)$ & $2.9(1.7-4.1)$ & \\
\hline $48 \mathrm{~h}$ & $2.3(1.6-3.1)$ & $2.5(1.7-3.4)$ & $0.009 / 0.027^{\mathrm{a}}$ \\
\hline \multicolumn{4}{|l|}{ fT4 (ng/dl) } \\
\hline Baseline & $14.8(9.6-19.7)$ & $15.0(9-19.2)$ & \\
\hline $24 \mathrm{~h}$ & $13.7(8.8-20.4)$ & $14.6(9.7-18.4)$ & \\
\hline $48 \mathrm{~h}$ & $12.6(0.2-19)$ & $14.0(11.1-24.4)$ & \\
\hline
\end{tabular}

TSH thyroid-stimulating hormone, $f T 3$ free triiodothyronine, $f T 4$ free thyroxine, $T$ time effect

${ }^{\text {a }}$ Paired $t$ test per group, 24 vs. $48 \mathrm{~h}$ 
Table 5 Time course of urinary electrolytes, creatinine, and osmolality

\begin{tabular}{|c|c|c|c|}
\hline & Saline group & Balanced group & Test, $p$ value \\
\hline \multicolumn{4}{|l|}{$N$ baseline } \\
\hline $\mathrm{Na} / \mathrm{K}$ & $14 / 17$ & $17 / 17$ & \\
\hline $\mathrm{Cl} /$ Osmolal. & $17 / 16$ & $16 / 17$ & \\
\hline \multicolumn{4}{|l|}{$N 24 \mathrm{~h}$} \\
\hline $\mathrm{Na} / \mathrm{K}$ & $18 / 17$ & $17 / 17$ & \\
\hline Cl/Osmolal. & $18 / 18$ & $17 / 16$ & \\
\hline \multicolumn{4}{|l|}{$N 48 \mathrm{~h}$} \\
\hline $\mathrm{Na} / \mathrm{K}$ & $14 / 10$ & $10 / 10$ & \\
\hline Cl/Osmolal. & $14 / 14$ & $10 / 10$ & \\
\hline \multicolumn{4}{|c|}{ Sodium (Mmol/L) } \\
\hline Baseline & $104 \pm 49$ & $75 \pm 42$ & \\
\hline $24 \mathrm{~h}$ & $83 \pm 59$ & $117 \pm 45$ & \\
\hline $48 \mathrm{~h}$ & $119 \pm 45$ & $96 \pm 42$ & \\
\hline \multicolumn{4}{|c|}{ Potassium (Mmol/L) } \\
\hline Baseline & $52 \pm 40$ & $48 \pm 32$ & $\mathrm{~T}, 0.029$ \\
\hline $24 \mathrm{~h}$ & $42 \pm 14$ & $34 \pm 21$ & \\
\hline $48 \mathrm{~h}$ & $39 \pm 31$ & $30 \pm 17$ & \\
\hline \multicolumn{4}{|c|}{ Chloride (Mmol/L) } \\
\hline Baseline & $100 \pm 59$ & $89 \pm 55$ & TG, 0.034 \\
\hline $24 \mathrm{~h}$ & $95 \pm 55$ & $120 \pm 50$ & \\
\hline $48 \mathrm{~h}$ & $132 \pm 42$ & $95 \pm 37$ & $0.032 /$ n.s. $^{\mathrm{a}}$ \\
\hline \multicolumn{4}{|c|}{ Osmolality (Mosmol/kg) } \\
\hline Baseline & $550 \pm 171$ & $562 \pm 203$ & \\
\hline $24 \mathrm{~h}$ & $566 \pm 124$ & $563 \pm 144$ & \\
\hline $48 \mathrm{~h}$ & $614 \pm 203$ & $535 \pm 160$ & \\
\hline
\end{tabular}

$T G$ time-group interaction, $T$ time effect

${ }^{\text {a }}$ Paired $t$ test per group, 24 vs. $48 \mathrm{~h}$

\section{Discussion}

The main findings of this blinded, randomized study are that a saline-based infusion regimen was associated with a higher sodium input compared to sodium excretion during the first $24 \mathrm{~h}$. More patients had a fluid balance $>1,500 \mathrm{~mL}$ during this time, and serum sodium, chloride, and osmolality increased, and metabolic acidosis was more frequent compared to the balanced infusion regimen.

Since hyponatremia after SAH may be an independent risk factor for poor outcome [4, 15], infusions with lower sodium content than normal saline could theoretically be harmful. However, uncontrolled prospective studies rather suggest a relationship between hyponatremia and excessive natriuresis and volume contraction [16, 17]. Volume contraction has been linked to symptomatic vasospasm [18], and fluid restriction has been associated with an increased incidence of delayed ischemic deficits [16]. In several uncontrolled studies, the development of volume contraction was found to be ameliorated by the administration of large amounts of fluids [17, 19]. In another study, however, only hyponatremia but not decreased circulating blood volume was prevented by administration of large amounts of sodium and water, adapted to renal excretion [20]. The guidelines of the American Heart Association [21] recommend that volume contraction be treated with isotonic fluids (Class IIa, Level of Evidence B), and that "administration of large volumes of hypotonic fluids should generally be avoided after SAH (Class I, Level of Evidence B)". Similarly, the very recently released guidelines of the Neurocritical Care Society for the management of patients with SAH recommend avoiding large amounts of free water intake and avoiding fluid restriction to treat hyponatremia [22]. Neither set of guidelines addresses the composition of baseline fluid administration in patients without oral intake.

Our data suggest that volume administration using either hypotonic or isotonic fluids during the first 2 days after $\mathrm{SAH}$ is associated with normal average serum sodium concentrations and a large variability in daily fluid balance, despite an overall increase in central venous blood pressure. Interestingly, while the amount of sodium administration was similar in both groups, this amount was significantly higher than sodium excretion during the first $24 \mathrm{~h}$ in the saline but not the balanced group. Since we investigated only a relatively small group of patients, and performed a large number of statistical comparisons, our results have to be interpreted with caution. Future studies should record the exact reasons why fluids are administered in these patients.

During the short observation period in our study, inappropriate $\mathrm{ADH}$ secretion and cerebral salt wasting syndrome were not an issue: only two patients presented with a serum sodium concentration $<135 \mathrm{mmol} / \mathrm{L}$, which resolved in one. In other studies with longer observation periods, hyponatremia developed frequently after SAH [1,23] and was associated with negative sodium balance $[1,24]$ and fluid balance [25]. The authors found almost uniformly increased ANP and/or BNP concentrations and delayed activation of the renin-aldosterone axis [1, 2, 24]. Unfortunately, we did not measure ANP, BNP, or renin/aldosterone concentrations, and therefore cannot evaluate their potential contribution to our findings. Nevertheless, we may speculate that the numerically lower osmotic clearance in the saline group during the first day, together with the positive sodium balance, suggests a shift of the ANP/BNP-aldosterone balance toward aldosterone in the saline group. Of note, hypernatremia (sodium concentration $>145 \mathrm{mmol} / \mathrm{L}$ ) was only present in 3 out of the 18 patients in the saline group.

Normal responses to administration of large amounts of hypotonic fluids are diminished anti-diuretic hormone secretion and decreased activation of the renin-angiotensin axis (unless tubular chloride concentrations become low). Consequently, one would expect higher free water clearance in the balanced group, which tended to be the case 
during the first $24 \mathrm{~h}$. Divergent alterations in cortisol and/ or thyroid hormone metabolism in the two groups can be excluded as an alternative explanation, since basal cortisol and fT3 decreased similarly in both groups and basal TSH did not change in either group. It seems therefore unlikely that the administration of corticosteroids to 11 vs. 6 patients in the saline versus balanced group has influenced our results. Nevertheless, it has been demonstrated that corticosteroids can influence water and sodium balance after subarachnoidal hemorrhage [26, 27].

Fluid balance was not associated with arterial hypertension or the use of steroids or norepinephrine. However, fluid balance was significantly higher in patients with more severe SAH (Hunt and Hess grades 3 and 4); this was accompanied by lower osmotic and free water clearances compared to patients with Hunt and Hess grades 1 and 2, suggesting again a different profile of ANP, BNP, and renin/aldosterone between these two patient groups.

Hypokalemia was frequent in both groups and not explained by the use of diuretics. A high incidence of hypokalemia in $\mathrm{SAH}$, especially in female patients, has previously been described [28, 29]. Hypokalemia has been attributed to stimulation of $\beta$-adrenoceptor and activation of membrane $\mathrm{Na}^{+} / \mathrm{K}^{+}$-ATPase [30]. Indeed, in our study, we found slightly lower serum potassium concentrations in patients who received norepinephrine during the first $24 \mathrm{~h}$ compared to those who did not.

Myocardial dysfunction is related to the severity of subarachnoidal hemorrhage [31]. Myocardial dysfunction may have influenced renal function and water clearance in our study as well. We measured troponin I only in half of the patients, and found no differences between groups.

Patients in the two groups had similar lengths of stay in the ICU and in the hospital, and the occurrence of neurological deficits was similar between groups after $48 \mathrm{~h}$ of treatment. Likewise, the modified Rankin scale at hospital discharge did not show differences between groups. Since the distinct infusion regimens were only maintained for $48 \mathrm{~h}$ and the number of patients in each group was fairly low, outcome was not our primary endpoint and should be interpreted very cautiously. Future studies should evaluate effects of different fluid regimen over a longer time period since the pathophysiology of fluid and electrolyte homeostasis and the response to the respective intervention may change over time in patients with subarachnoidal hemorrhage.

\section{Conclusions}

We conclude that in our small cohort of patients, $48 \mathrm{~h}$ of treatment with saline-based fluids resulted in a greater number of patients with hyperchloremia, hyperosmolality, metabolic acidosis, and positive fluid balance $>1,500 \mathrm{~mL}$ during the first day. Administration of balanced solutions did not cause more frequent hyponatremia or hypo-osmolality. These results should be confirmed in studies including larger numbers of patients and a longer treatment period.

Acknowledgments We are grateful for skillful assistance by the research nurses Judith Erni-Kaufmann, Natalie Araya-Araya, Michael Lensch, Konrad Torsten, and for careful editing of the manuscript by Jeannie Wurz, medical writer. Supported by an unrestricted grant from BBraun Medical AG, Sempach, Switzerland.

Conflict of interest The Department of Intensive Care Medicine has, or has had in the past, research contracts with Abbott Nutrition International, CSEM SA, Edwards Lifesciences Services GmbH, Kenta Biotech Ltd, Maquet Critical Care AB, Omnicare Clinical Research AG, and Orion Corporation; and research \& development/ consulting contracts with Edwards Lifesciences SA, Maquet Critical Care $\mathrm{AB}$, and Néstle. The money is/was paid into a departmental fund; no author receives/received any personal financial gain. The department has received unrestricted educational grants from the following organizations for organizing a quarterly postgraduate educational symposium, the Berner Forum for Intensive Care: Fresenius Kabi; gsk; MSD; Lilly; Baxter; astellas; AstraZeneca; BIBraun; CSL Behring; Maquet; Novartis; Covidien; Mycomed; RobaPharma.

\section{References}

1. Berendes E, Walter M, Cullen P, et al. Secretion of brain natriuretic peptide in patients with aneurysmal subarachnoid haemorrhage. Lancet. 1997;349:245-9.

2. Espiner EA, Leikis R, Ferch RD, et al. The neuro-cardio-endocrine response to acute subarachnoid haemorrhage. Clin Endocrinol (Oxf). 2002;56:629-35.

3. Wartenberg KE, Schmidt JM, Claassen J, et al. Impact of medical complications on outcome after subarachnoid hemorrhage. Crit Care Med. 2006;34:617-23.

4. Hasan D, Wijdicks EF, Vermeulen M. Hyponatremia is associated with cerebral ischemia in patients with aneurysmal subarachnoid hemorrhage. Ann Neurol. 1990;27:106-8.

5. Qureshi AI, Suri MF, Sung GY, et al. Prognostic significance of hypernatremia and hyponatremia among patients with aneurysmal subarachnoid hemorrhage. Neurosurgery. 2002;50:749-55.

6. Mandal AK, Saklayen MG, Hillman NM, Markert RJ. Predictive factors for high mortality in hypernatremic patients. Am J Emerg Med. 1997;15:130-2.

7. Bennani SL, Abouqal R, Zeggwagh AA, et al. Incidence, causes and prognostic factors of hyponatremia in intensive care. Rev Med Interne. 2003;24:224-9.

8. Lee CT, Guo HR, Chen JB. Hyponatremia in the emergency department. Am J Emerg Med. 2000;18:264-8.

9. Tommasino C, Moore S, Todd MM. Cerebral effects of isovolemic hemodilution with crystalloid or colloid solutions. Crit Care Med. 1988;16:862-8.

10. Zornow MH, McQuitty C, Prough DS. Perioperative fluid management of the neurosurgical patient. In: Albin MS, editor. Textbook of neuroanesthesia with neurosurgical and neuroscience perspectives. New York: McGraw-Hill; 1997. p. 117-48.

11. Williams EL, Hildebrand KL, McCormick SA, Bedel MJ. The effect of intravenous lactated Ringer's solution versus $0.9 \%$ sodium chloride solution on serum osmolality in human volunteers. Anesth Analg. 1999;88:999-1003. 
12. O’Malley CM, Frumento RJ, Hardy MA, et al. A randomized, double-blind comparison of lactated Ringer's solution and $0.9 \%$ $\mathrm{NaCl}$ during renal transplantation. Anesth Analg. 2005;100: 1518-24.

13. Wilkes NJ, Woolf R, Mutch M, et al. The effects of balanced versus saline-based hetastarch and crystalloid solutions on acidbase and electrolyte status and gastric mucosal perfusion in elderly surgical patients. Anesth Analg. 2001;93:811-6.

14. Van Swieten JC, Koudstaal PJ, Visser MC, Schouten HJ, van Gijn J. Interobserver agreement for the assessment of handicap in stroke patients. Stroke. 1988;19:604-7.

15. Sayama T, Inamura $T$, Matsushima $T$, Inoha $S$, Inoue T, Fukui M. High incidence of hyponatremia in patients with ruptured anterior communicating artery aneurysms. Neurol Res. 2000;22:151-5.

16. Wijdicks EF, Vermeulen M, ten Haaf JA, Hijdra A, Bakker WH, van Gijn J. Volume depletion and natriuresis in patients with a ruptured intracranial aneurysm. Ann Neurol. 1985;18:211-6.

17. Diringer MN, Wu KC, Verbalis JG, Hanley DF. Hypervolemic therapy prevents volume contraction but not hyponatremia following subarachnoid hemorrhage. Ann Neurol. 1992;31:543-50.

18. Solomon RA, Post KD, McMurtry JG 3rd. Depression of circulating blood volume in patients after subarachnoid hemorrhage: implications for the management of symptomatic vasospasm. Neurosurgery. 1984;15:354-61.

19. Hasan D, Lindsay KW, Wijdicks EF, et al. Effect of fludrocortisone acetate in patients with subarachnoid hemorrhage. Stroke. 1989;20:1156-61.

20. Audibert G, Steinmann G, de Talancé N, et al. Endocrine response after severe subarachnoid hemorrhage related to sodium and blood volume regulation. Anesth Analg. 2009;108:1922-8.

21. Bederson JB, Connolly ES Jr, Batjer HH, American Heart Association, et al. Guidelines for the management of aneurysmal subarachnoid hemorrhage: a statement for healthcare professionals from a special writing group of the Stroke Council, American Heart Association. Stroke. 2009;40:994-1025.
22. Diringer M, Bleck T, Claude Hemphill J, et al. Critical care management of patients following aneurysmal subarachnoid hemorrhage: recommendations from the Neurocritical Care Society's multidisciplinary consensus conference. Neurocrit Care. 2011;15:211-40.

23. Isotani E, Suzuki R, Tomita K, et al. Alterations in plasma concentrations of natriuretic peptides and antidiuretic hormone after subarachnoid hemorrhage. Stroke. 1994;25:2198-203.

24. Kurokawa Y, Uede T, Ishiguro M, et al. Pathogenesis of hyponatremia following subarachnoid hemorrhage due to ruptured cerebral aneurysm. Surg Neurol. 1996;46:500-7.

25. Wijdicks EF, Schievink WI, Burnett JC Jr. Natriuretic peptide system and endothelin in aneurysmal subarachnoid hemorrhage. J Neurosurg. 1997;87:275-80.

26. Moro N, Katayama Y, Kojima J, Mori T, Kawamata T. Prophylactic management of excessive natriuresis with hydrocortisone for efficient hypervolemic therapy after subarachnoid hemorrhage. Stroke. 2003;34:2807-11.

27. Katayama Y, Haraoka J, Hirabayashi H, et al. A randomized controlled trial of hydrocortisone against hyponatremia in patients with aneurysmal subarachnoid hemorrhage. Stroke. 2007;38:2373-5.

28. Fukui S, Otani N, Katoh H, et al. Female gender as a risk factor for hypokalemia and QT prolongation after subarachnoid hemorrhage. Neurology. 2002;59:134-6.

29. Fukui S, Katoh H, Tsuzuki N, et al. Multivariate analysis of risk factors for QT prolongation following subarachnoid hemorrhage. Crit Care. 2003;7:R7-12.

30. Brown MJ, Brown DC, Murphy MB. Hypokalemia from beta2receptor stimulation by circulating epinephrine. N Engl J Med. 1983;309:1414-9.

31. Mayer SA, Lin J, Homma S, et al. Myocardial injury and left ventricular performance after subarachnoid hemorrhage. Stroke. 1999;30:780-6. 